\title{
Growth and shrinkage in Antarctic krill Euphausia superba is sex-dependent
}

\author{
G. A. Tarling ${ }^{1, *}$, S. Hill ${ }^{1}$, H. Peat ${ }^{1}$, S. Fielding ${ }^{1}$, C. Reiss ${ }^{2}$, A. Atkinson ${ }^{3}$ \\ ${ }^{1}$ British Antarctic Survey, Natural Environment Research Council, High Cross, Madingley Road, Cambridge CB3 0ET, UK \\ ${ }^{2}$ Southwest Fisheries Science Center, 8604 La Jolla Shores Drive, La Jolla, CA 92037, USA \\ ${ }^{3}$ Plymouth Marine Laboratory, Prospect Place, The Hoe, Plymouth PL1 3DH, UK
}

\begin{abstract}
The ability of Antarctic krill Euphausia superba Dana to withstand the overwintering period is critical to their success. Laboratory evidence suggests that krill may shrink in body length during this time in response to the low availability of food. Nevertheless, verification that krill can shrink in the natural environment is lacking because winter data are difficult to obtain. One of the few sources of winter krill population data is from commercial vessels. We examined length-frequency data of adult krill (>35 mm total body length) obtained from commercial vessels in the Scotia-Weddell region and compared our results with those obtained from a combination of science and commercial sampling operations carried out in this region at other times of the year. Our analyses revealed body-length shrinkage in adult females but not males during winter, based on both the tracking of modal size classes over seasons and sex-ratio patterns. Other explanatory factors, such as differential mortality, immigration and emigration, could not explain the observed differences. The same pattern was also observed at South Georgia and in the Western Antarctic Peninsula. Fitted seasonally modulated von Bertalanffy growth functions predicted a pattern of overwintering shrinkage in all body-length classes of females, but only stagnation in growth in males. This shrinkage most likely reflects morphometric changes resulting from the contraction of the ovaries and is not necessarily an outcome of winter hardship. The sex-dependent changes that we observed need to be incorporated into life cycle and population dynamic models of this species, particularly those used in managing the fishery.
\end{abstract}

KEY WORDS: Southern Ocean $\cdot$ Population dynamics $\cdot$ Production $\cdot$ Life cycle $\cdot$ Fishery

\section{INTRODUCTION}

Antarctic krill Euphausia superba has long been recognised as an integral component of many Antarctic marine food webs (Marr 1962, Miller \& Hampton 1989, Hill et al. 2012) as a result of its high levels of abundance globally (Everson 1977, Gulland 1983, Atkinson et al. 2009), its nutritional content (Pond et al. 1995) and its tendency to form swarms and thus concentrate biomass (Clarke 1984, El-Sayed \& McWhinnie 1979, Tarling et al. 2009). For these same reasons, it is also a readily exploitable resource (Miller and Agnew 2000) and it has now been commercially harvested for almost $40 \mathrm{yr}$. The fishery is

*Corresponding author: gant@bas.ac.uk managed under the Convention for the Conservation of Antarctic Marine Living Recourses (CCAMLR), which recognises the need to limit fishery impacts on both the krill stock and the predator populations that feed on it. The fishery is currently managed with an interim catch limit and CCAMLR is actively developing a long-term management approach.

Effective fisheries management relies on a good understanding of the population dynamics of the exploited resource (Hilborn \& Walters 1992, Quinn \& Deriso 1999). These dynamics are often represented in models that assimilate data to assess stock status (Kinzey et al. 2015) and project the consequences of future fishing. Critical population parameters in such

() The authors 2016. Open Access under Creative Commons by Attribution Licence. Use, distribution and reproduction are unrestricted. Authors and original publication must be credited. 
models include rates of recruitment, mortality and growth, total lifespan and maximum body size (Constable \& de la Mare 1996, Miller \& Agnew 2000). Nevertheless, estimation of some of these parameters for Antarctic krill is far from straightforward and is still subject to some controversy (Rosenberg et al. 1986, Siegel \& Nicol 2000, Kawaguchi et al. 2006, 2007). In particular, growth rate has been shown to be highly variable, both temporally (Kawaguchi et al. 2006) and spatially (Quetin et al. 2003, Atkinson et al. 2006), making the relationship between age and body length a complex one (Nicol 2000).

One of the major factors affecting the population dynamics of Antarctic krill is the extended winter period, when food resources are limited. As well as using lipid reserves and various alternative winter food sources and feeding substrates (Quetin et al. 1994, Schmidt et al. 2011, Meyer 2012), krill also appear capable of utilising protein in somatic tissue and shrinking in body size during periods of low food intake. This is clearly seen in field populations of larval krill during their first overwintering period (Daly 2004, Meyer 2012). In adults, reports of shrinkage have mainly come from laboratory incubation studies. Ikeda \& Dixon (1982) maintained adult Antarctic krill in starved conditions for $211 \mathrm{~d}$, during which time their body mass decreased by $45 \%$, equivalent to a decrease in body length of $0.033 \mathrm{~mm} \mathrm{~d}^{-1}$. In a large batch of adult krill maintained at Palmer station (Antarctic Peninsula), McWhinnie et al. (1979) reported shrinkage of $23 \%$ in body length in specimens maintained during an overwintering period. Bodylength shrinkage has since been reported in both short- and long-term incubation studies (Nicol et al. 1992, Kawaguchi et al. 2006). Candy \& Kawaguchi (2006) modelled a number of datasets generated from incubation studies and concluded that maximum body lengths were better predicted when allowing individuals to shrink during overwintering periods.

Because the low-food conditions last for a large fraction of the year, whether growth is positive, negative or zero during this time has a large influence on our estimates of size at age and longevity. From initial estimates of a 2 to 3 yr life cycle in Antarctic krill (Bargmann 1945, Marr 1962, Mackintosh 1972), there is now a greater consensus that typical life cycles last approximately 5 to 6 yr (Rosenberg et al. 1986, Nicol 2000), by which time adults have spawned in 2 or 3 summer seasons (Cuzin-Roudy 2000) and reached body lengths of between 55 and $65 \mathrm{~mm}$ (Schmidt et al. 2014). However, there is still uncertainty around whether the pattern of growth is the same in males and females (Kawaguchi et al.
2006). Siegel \& Loeb (1994), for instance, considered that males took $1 \mathrm{yr}$ more than females to attain sexual maturity. However, Kawaguchi et al. (2007) posited that males matured earlier than females, and were more likely to have a shorter life cycle, dying at a younger age than females. Resolution of this issue is critical to understanding patterns of sex-ratio bias over the course of the year, with further implications to recruitment and harvesting.

Another notable biological feature of both male and female Antarctic krill is their ability to regress secondary sexual characters. McWhinnie et al. (1979) observed this phenomenon while incubating specimens over winter. These individuals returned to previous maturity stages the following summer. Thomas \& Ikeda (1987) found the same pattern of regression when exposing incubated specimens to sub-optimal food conditions. These results provided support to the earlier assertion by Makarov (1976) that sexual regression must be taking place in field populations, given his observation of a high incidence of sexually immature specimens in August.

Despite laboratory evidence that krill are capable of decreasing their body size and regressing their sexual characters, there remains considerable debate over whether such traits are common in adult field populations, particularly with regards to body-length frequency distributions (Quetin et al. 1994). For instance, Ettershank (1983) concluded that there was bodylength shrinkage during winter in samples taken by Stepnik (1982) from the South Shetland Islands (Western Antarctic Peninsula [WAP]). However, in a reanalysis of this data, McClatchie (1988) found slow positive growth. Quetin \& Ross (1991) found negative in situ growth in adult krill collected in the Bransfield Strait (WAP) in August and September 1985.

Body-size distribution data are difficult to interpret in situations where there may also be size-selective mortality, immigration and emigration taking place in the sampled population. This is compounded by the fact that Antarctic krill populations are in a constant state of flux through their interactions with the strongly advective Southern Ocean currents (Thorpe et al. 2004, 2007). Certain age classes may be missing within a study area at any one particular sampling period, and the situation may change dramatically between sampling periods. A further difficulty is that very few scientific sampling operations are carried out during the winter period, necessitating a certain level of inference on overwintering population dynamics. By contrast, commercial trawling for Antarctic krill has been very active during the austral winter. Body-length distributions, sex and develop- 
ment stage are measured by observers on krill fishing vessels and reported to CCAMLR. In total, these measurements have been made on more than 180000 krill over the winter period.

In this study, we combine thousands of net samples on which size distribution, sex and maturity were measured. Science-net samples collected over decades of sampling have been collated within the KRILLBASE database (Atkinson et al. 2009), whereas data from fishery catches have been compiled by CCAMLR (www.ccamlr.org). We focus this study on the Scotia-Weddell region (from ice-edge to Polar Front), where some of the highest concentrations of krill biomass occur (Atkinson et al. 2008) and almost all of the krill fishery operates (Croxall \& Nicol 2004). In carrying out analyses on large-scale, long-term data sets, we overcome one of the main difficulties of inferring more general patterns from relatively small-scale surveys, which has beset many previous studies of Antarctic krill population dynamics (Miller \& Hampton 1989). This study also makes a particular focus of the overwintering period through utilisation of data provided by the winter fishery, allowing direct observations of how size-distribution patterns change during this poorly observed period and how this influences present interpretations of growth trajectories and life-cycle duration. Finally, in line with the recommendations of a recent study (Kawaguchi et al. 2007), the population dynamics of females and males were considered separately, to elucidate differences in growth trajectories and the relative timing of sexual maturity in both sexes.

\section{METHODS}

\section{Databases}

Two main databases of individual krill measurements were used to analyse the population dynamics of Antarctic krill: one comprising data collected as part of scientific surveys (KRILLBASE, Atkinson et al. 2009; see Supplement 1 at www.int-res.com/articles/ suppl/m547p061_supp.pdf), the other comprising data collected by observers on fishery operations as part of CCAMLR, (www.ccamlr.org; see Supplement 2 at www.int-res.com/articles/suppl/m547p061_supp.pdf). KRILLBASE contains measurements collected mainly between October and April (summer) whereas the CCAMLR data are more evenly spread between summer and winter, although records were lacking for certain periods of the summer. Population dynamic analyses were based on a combination of these databases, where KRILLBASE data were used to assess the summer situation and CCAMLR data were used to assess the situation during the overwintering period. Differences in collection and measurement methods, both within and between databases, necessitated a number of comparisons to be made to identify the major biases. In particular, CCAMLR summer records were compared with those of KRILLBASE to identify methodological biases between the databases. These comparisons led to the implementation of a number of pre-treatments to minimise error and bias when determining population structure. The analyses were focused on the Scotia-Weddell region, which we defined as being between the longitudes $60^{\circ} \mathrm{W}$ and $20^{\circ} \mathrm{W}$ and south of latitude $56^{\circ} \mathrm{S}$. The decision to limit the analyses to this region was made to minimise the impact of geographic factors on our results, while encompassing the largest possible body of population data. Comparisons to other geographic regions (South Georgia and WAP) were performed subsequently to examine levels of spatial coherence in patterns of population dynamics.

\section{KRILLBASE}

In KRILLBASE, there were 3402 net hauls in the Scotia-Weddell region on which body-length frequency measurements were made. They span from the Discovery Investigations (1926-1939) through to the modern era. The hauls were carried out in both a targeted or untargeted manner and were thus a mix of horizontal, oblique and vertical deployments. The majority of hauls $(98.6 \%)$ were taken between October and April, where a total of 317335 individuals were measured. Body-length measurements were mostly made from the front of the eye to the tip of the telson (AT; Morris et al. 1988). Maturity status was specified to different degrees of resolution according to several different schemes (see below).

\section{CCAMLR database}

This database has been compiled by the CCAMLR data centre (www.ccamlr.org/) from submissions to the Secretariat under rules adopted by the TwentySecond Meeting of the Commission (CCAMLR-XXII, paragraphs 12.1 to 12.6$)$. The database covers observations made on fishery operations between 2000 and 2013, which comprised a total of 7538 hauls made from 134 separate fishing expeditions. Approximately half (3290 hauls) were performed in the 
Scotia-Weddell region, comprising 1334 hauls during winter (May to September) and 1956 hauls in summer (October to April). This provided 184931 and 184161 individuals measured in winter and summer, respectively, although it is to be noted that that there were no recorded catches in November and April. Total body length (mm), sex and sexual development stage were recorded for each individual, following CCAMLR protocols specified in www.ccamlr.org/en/ system/files/obsman.pdf. According to these protocols, total body length measurements were made from the front of the eye to the tip of the telson ( $A T$; Morris et al. 1988) to the nearest millimetre. Sex and sexual development stage were classified according to (1) the presence of a petasma: male ${ }_{i}(2)$ the presence of a thelycum: female; or (3) the absence of either external organ: juvenile. In the case of females, those with swollen carapaces were further classified as being gravid.

The winter population structure in the Scotia-Weddell region was compared with that found at South Georgia and the WAP during the same period. The South Georgia region was defined as being within the limits of $56^{\circ} \mathrm{S}$ and $50^{\circ} \mathrm{S}$, and $40^{\circ} \mathrm{W}$ and $34^{\circ} \mathrm{W}$, whereas the limits of the WAP were defined as $65^{\circ} \mathrm{S}$ to $62^{\circ} \mathrm{S}$, and $64^{\circ} \mathrm{W}$ to $60^{\circ} \mathrm{W}$. Between May and September, the CCAMLR database for the South Georgia region contained a total of 435 separate net hauls, amounting to 23378 individuals. For the WAP region, the database contained 860 separate net hauls and 58134 individuals.

\section{Pre-treatment of data}

\section{Pooling of data}

Most net-sample catches reported measurements of between 30 and 200 individuals per haul and all individual measurements of krill body length, sex and maturity status were considered as discrete data points. In KRILLBASE, the maturity status of individuals was classified according to a number of different schemes, whereas in the CCAMLR database, 4 different categories were distinguished: juveniles, adult males, non-gravid adult females and gravid adult females. The lack of a universal scheme across all databases, plus the variance between scientists and observers in how these were applied, introduces further error in comparative analyses. Therefore, all maturity information was simplified into the following 3 categories: juvenile, male and female.

\section{Smoothing algorithm}

Body-length measurements in certain datasets were made in increments of $2 \mathrm{~mm}$ or, very infrequently, $3 \mathrm{~mm}$, rather than the more commonly measured $1 \mathrm{~mm}$ intervals. This was mitigated through applying the following 'moving-average' algorithm:

$$
n^{\prime}{ }_{x}=\frac{n_{x-1}}{4}+\frac{n_{x}}{2}+\frac{n_{x+1}}{4}
$$

where $n^{\prime}$ is the smoothed frequency of individuals, $n$ is the original frequency of individuals and $x$ is body length in increments of $1 \mathrm{~mm}$. For the first and last body-length increments, $n$ ' was determined as the average of that increment and the one adjacent to it.

\section{Component-fitting analysis}

Antarctic krill have a multi-year life cycle, so analysis of body-length frequency data necessitates the application of statistical methods to separate year classes into size-distribution modes. For this purpose, we applied the mixdist package (Ichthus data systems, www.math.mcmaster.ca/peter/mix/mix.html) in $\mathrm{R}$ (version 3.1.1) to body-length frequency data from both the KRILLBASE and CCAMLR databases. mixdist fits finite mixture distributions to population data, and is an update of the MIX programme, developed by Macdonald \& Pitcher (1979), with improved numerical methods based on a combination of the expectation-maximization algorithm (Dempster et al. 1977) and a Newton-type method (Du 2002). To apply the software, the user must identify the expected number of age components within the distribution before initialising the fitting procedure. The initial hypothesis, based on other observations (Rosenberg et al. 1986, Tarling et al. 2007), was that there were 3 log-normal components in the post-larval population of Antarctic krill, with modal peaks at 35, 45 and $55 \mathrm{~mm}$. Further runs with 2 and 4 modes at various assumed modal peaks were also performed to consider whether better fits could be achieved with alternative assumptions. As a starting point for the fitting procedure, the initial proportions in each component were assumed to be equal and there were no constraints put on the proportions, mean body lengths and variances in each component. Further fits were attempted by reducing or increasing the number of components and also assuming that components were normally distributed. 
Before applying the mixdist fitting procedure, the databases were divided into 3 periods of the year: early productive period (October to December), late productive period (January to April) and overwintering (May to September). KRILLBASE was used in the early and late productive period datasets, whereas CCAMLR data were used for the overwintering dataset. The CCAMLR summer dataset was not included in certain analyses, particularly those considering growth, because of the absence of records in 2 out of the 7 months. Nevertheless, the dataset was used to consider seasonally integrated patterns in bodylength frequency and length-specific sex ratio. The CCAMLR summer dataset was also used in analyses to identify biases between the CCAMLR and KRILLBASE datasets.

In each period, 3 subsets were generated: (1) all length frequency data (sexes combined), (2) female data only and (3) male data only. Fits by mixdist to the body-length frequency distributions of each subset were ranked according to their chi-squared goodness-of-fit values. In some instances, some high-ranking fits contained components with unrealistic levels of variance or very small intercomponent distances, and these were subsequently rejected.

\section{Sexual regression}

Antarctic krill can lose their secondary sexual characteristics during winter and take on a juvenile external appearance (Ikeda \& Thomas 1987, Siegel 2012). Therefore, a potential explanation for any seasonal changes in the proportion of males and females is that one sex regresses to a juvenile state more than another (regression bias). An associated problem is the misclassification of maturity status and sex by observers when secondary sexual characters are either still developing or in a state of regression. This could have an influence similar to that of real regression bias if misclassifications are more common for one sex than the other (misclassification bias). We considered how regression bias and misclassification bias could alter sex ratio through a series of sensitivity analyses.

In simulations, it was assumed that all juveniles in the CCAMLR winter population had developed secondary sexual characteristics during the previous summer and had since regressed to a juvenile state (termed henceforth as ex-females and ex-males). For the purpose of the analysis, ex-females and ex-males represent individuals that have either genuinely regressed or have otherwise been misclassified as having regressed. The proportion of ex-females to ex-males was then varied such that, at one extreme, there was $10 \%$ ex-females to $90 \%$ ex-males and, at the other, $90 \%$ ex-females to $10 \%$ ex-males. The exfemale and ex-male populations were added to the overwintering adult population and the proportion of males (PM) per body-length interval was determined. These simulated PM to body-length distributions were compared with those observed in the summer to consider whether any differences could be explained by sex-related skew in sexual-regression.

\section{Growth trajectories}

Seasonally modulated von Bertalanffy functions (sVBFs; Pitcher \& MacDonald, 1973) were fitted to the modal peaks identified above (for a full description of this method, see Supplement 3 at www.intres.com/articles/suppl/m547p061_supp.pdf). Pitcher \& MacDonald (1973) developed 2 sVBFs: one in which the population switched between a period of positive growth and a period of zero growth (the switched-growth model) and another where the seasonal change in growth rate occurred more smoothly and allowed for negative growth (the sine-wave growth model). Attempts were made to fit both growth models with a distance minimisation algorithm (Microsoft Excel 2007 Solver: Generalised Reduced Gradient [GRG2] nonlinear optimisation), using initial estimates of the growth constant $K$ from Siegel (1987) and setting the upper body-length size limit $\left(L_{\text {inf }}\right)$ at $65 \mathrm{~mm}$ and solving for all other sVBF parameters. A single set of parameter values did not fit both the smaller and larger body-length modes equally well, so further fits were attempted by splitting the observed data set into smaller and larger body lengths and fitting the sVBF to each dataset separately. The split point was made at 1 of 4 different points in the life cycle (1st week in November or July in years $2+$ or $3+$ ), representing the points at which growth was, respectively, highest and lowest within the annual cycle. The preferred sVBF parameter values and split-points were those that achieved the minimum squared-difference.

\section{Validation: simulations of overwintering population}

Simulations were performed to consider the level of agreement between population size-structure in the late productive-season and overwinter, once the 
fitted sVBF functions had been factored in. The total body length of each individual measured in the late productive season dataset $\left(L_{t, 1 \mathrm{~s}}\right)$ was altered by a growth factor $R_{\mathrm{t}}$ to predict a mid-overwintering total body length, $L_{\mathrm{t}, \mathrm{ow}^{\prime}}$, as follows:

$$
L_{\mathrm{t}, \mathrm{ow}}=L_{\mathrm{t}, \mathrm{ls}}+R_{\mathrm{t}}
$$

$R_{\mathrm{t}}$ was a randomised variable with a mean equal to the difference in $L_{\mathrm{t}}$ between late productive season and overwintering according to the fitted sVBF function. Growth in body length between these 2 periods derives a positive value, and shrinkage derives a negative value. A randomised amount within the range of $\pm 1.5 \mathrm{~mm}$ was integrated within the $R_{\mathrm{t}}$ value applied to each individual to represent individual variance in growth and shrinkage. $R_{\mathrm{t}}$ was derived separately for each year class. The predicted and observed overwintering size structures were subsequently compared.

\section{RESULTS}

\section{Comparison of KRILLBASE and CCAMLR datasets}

A comparison was made between the summer (October to April) records of KRILLBASE and CCAMLR databases to identify any major differences in their respective body-length distributions. Both databases showed a concentration of sampling effort towards the tip of the Antarctic Peninsula and around the South Orkneys (Fig. 1). The least intensively sampled areas were towards the eastern and southern parts of the ScotiaWeddell region. The geographic extent of the CCAMLR database was more limited compared with that of KRILLBASE, particularly in the northwestern sector of the Scotia-Weddell region. By comparison, $61 \%$ of all krill and $63 \%$ of all catches within the KRILLBASE database occurred within the main CCAMLR fishing areas.

During summer, a peak in bodylength distributions occurred between 45 and $47 \mathrm{~mm}$ in both the KRILLBASE and CCAMLR databases (Fig. 2). Furthermore, comparative proportions were very similar between 40 and $53 \mathrm{~mm}$. At body lengths greater than this, there was a slight increase in the cumulative proportion of krill in the CCAMLR database. Below $40 \mathrm{~mm}$, and particularly below $35 \mathrm{~mm}$, the cumulative proportion in the CCAMLR database decreased from around $75 \%$ to less than $1 \%$ of the KRILLBASE dataset. When restricting KRILLBASE to the main CCAMLR fishing areas, the proportion of individuals in the smaller body-length classes was also depleted compared with the full KRILLBASE dataset (Fig. 2). Nevertheless, the pattern of this decrease was dif-



Fig. 1. Euphausia superba. Distribution of net hauls in the Scotia-Weddell region within KRILLBASE summer records (main map) and within the winter period of the CCAMLR dataset (inset) that were used for the analysis in this study. Key refers to number of hauls within a $2 \times 2^{\circ}$ grid cell 
Fig. 2. Euphausia superba. Body-length frequency distributions in the Scotia-Weddell region during summer (OctApr). Bars: all KRILLBASE records, divided according to maturity stage; filled circles: CCAMLR records; open triangles: KRILLBASE records restricted to the geographic regions covered by the CCAMLR records. Data were smoothed using a moving average algorithm. TL: total body length. Only size classes at or above $35 \mathrm{~mm}$ were included in modal class analyses

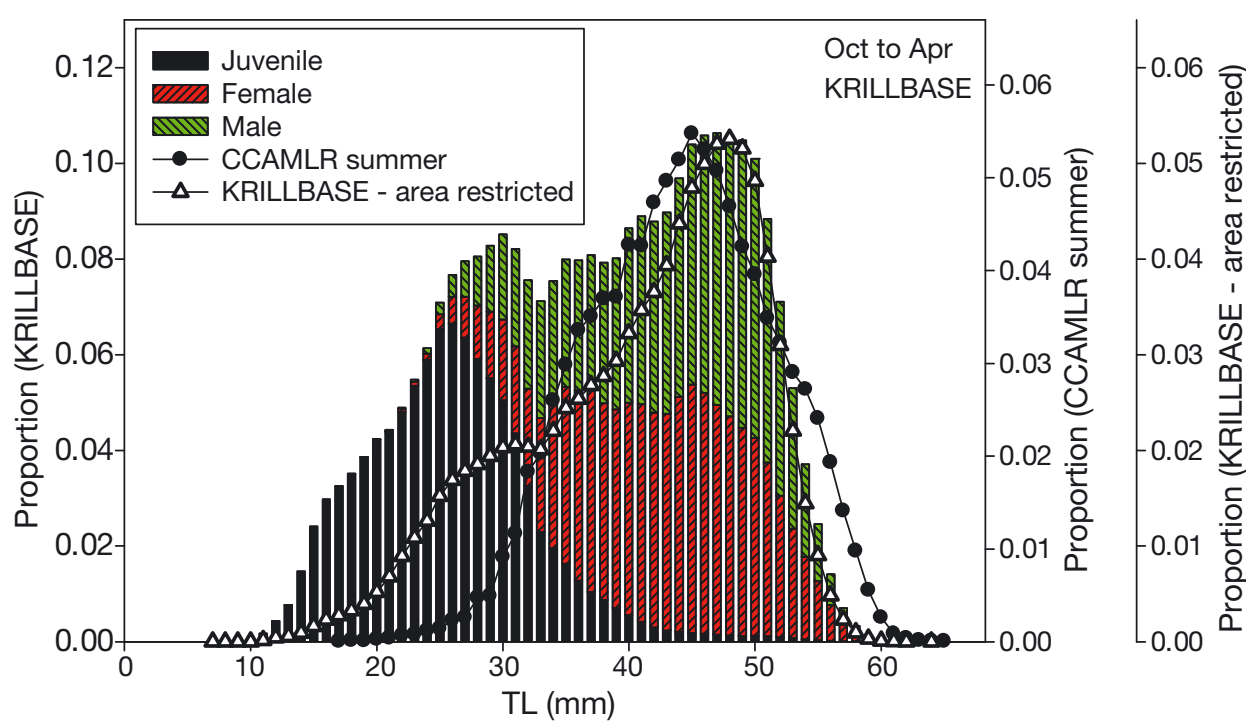

Adult population components

ferent to the CCAMLR dataset, given that the comparative proportion of krill $<35 \mathrm{~mm}$ remained around $75 \%$ of that observed in the full KRILLBASE dataset.

These comparisons show that there are differences in the body-length distributions of the KRILLBASE and CCAMLR datasets, which are a combination of both geographic and methodological factors. Nevertheless, it was only at body lengths smaller than $35 \mathrm{~mm}$ that differences were severe enough to affect component-fitting analysis. This is most likely due to the coarser mesh size of the commercial trawls. Therefore, modal classes below $35 \mathrm{~mm}$ identified in the CCAMLR winter dataset were not considered in any further interpretation of overwintering population structure.

\section{Population structure}

General population structure

Juveniles with body lengths of between 17 and $30 \mathrm{~mm}$ were a major contributor to the population during the early productive season (Fig. 3). These are probably a combination of individuals that have overwintered either once or twice. This pulse of new recruits was less evident in the late productive season, where the population was dominated by adults between 40 and $50 \mathrm{~mm}$ in body length. The adult population structure changed little moving into the overwintering period, but juvenile structure changed considerably, with a large fraction being evident between 40 and $50 \mathrm{~mm}$.
Component-fitting analysis consistently found 3 log-normal components to be the best fit to the adult population structure in all 3 seasons. In the early productive season, the 3 female components peaked at $32 \mathrm{~mm}$ (mode 1), $42 \mathrm{~mm}$ (mode 2) and $49 \mathrm{~mm}$ (mode $3)$, although the latter mode contained only a small proportion of the population (11\%; Fig. 4, Table 1). In the males, peaks were at larger body lengths: 33, 44 and $50 \mathrm{~mm}$, respectively.

In the late productive season, females in mode 3 increased substantially both in terms of peak body length $(51 \mathrm{~mm})$ and proportion $(21 \%)$. Growth was also seen in the earlier modes, which now peaked at $40 \mathrm{~mm}$ (mode 1) and $46 \mathrm{~mm}$ (mode 2). In males, there was growth in mode 1 (peak at $36 \mathrm{~mm}$ ), but modes 2 and 3 peaked at approximately the same body lengths as observed in the early productive season (44 and $50 \mathrm{~mm}$, respectively).

During the overwintering period, although there were 3 clearly defined components in both the male and female populations, mode 1 was not considered further given the potential sampling bias in the CCAMLR dataset. In females, mode 2 peaked at $43 \mathrm{~mm}$ and mode 3 peaked at $47 \mathrm{~mm}$, which are 3 and $4 \mathrm{~mm}$ smaller, respectively, than these modes in the late productive season. In males, both mode 2 (44 $\mathrm{mm})$ and mode $3(50 \mathrm{~mm})$ peaked at approximately the same body lengths as observed at other times of year.

At a mean length of between 31 and $38 \mathrm{~mm}$, it is most likely that mode 1 within the productive season is equivalent to the $1+$ cohort, following Siegel 

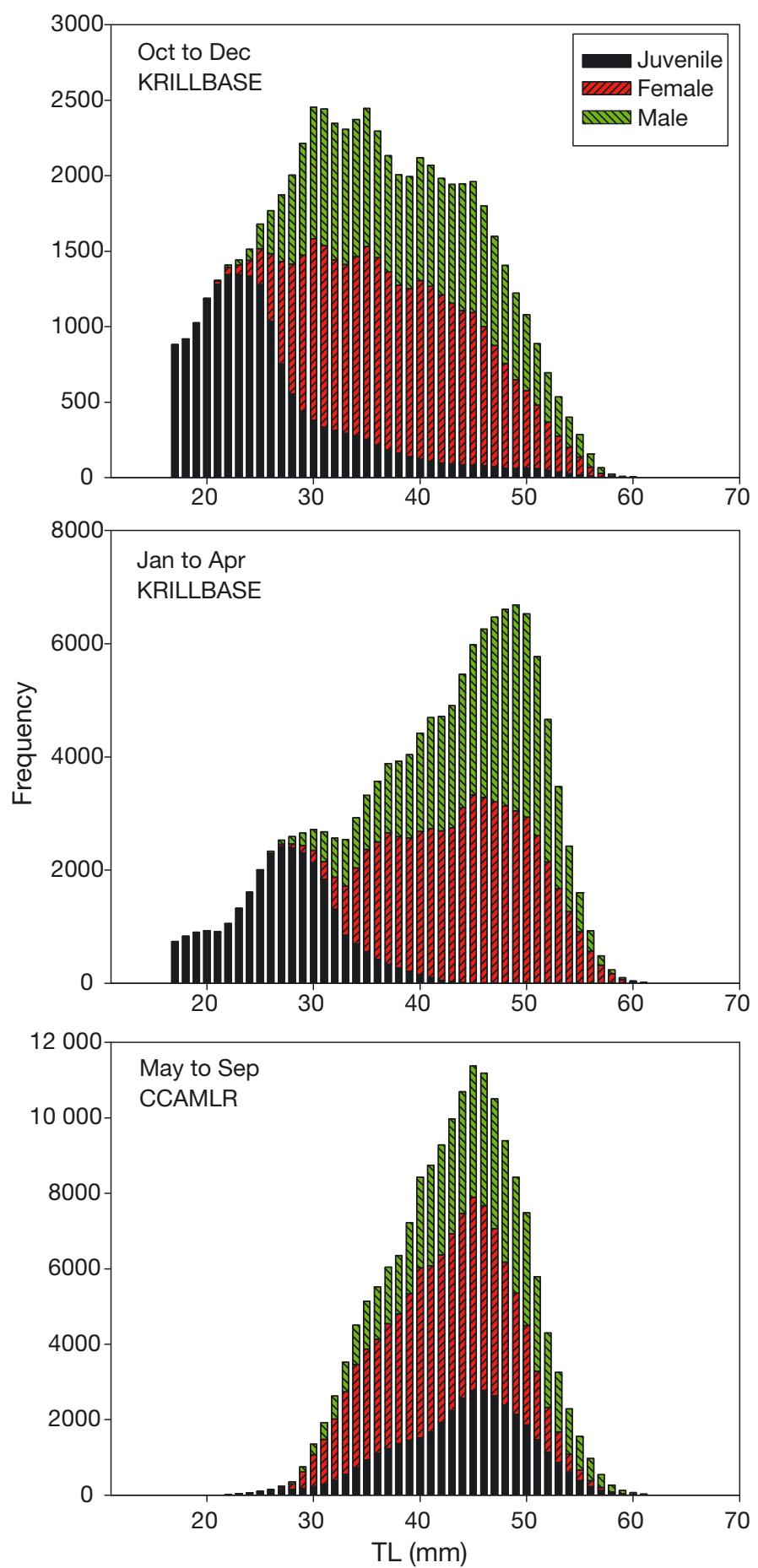

Fig. 3. Euphausia superba. Body-length frequency distributions of juveniles, females and males in the Scotia-Weddell region, divided into 3 seasonal periods. Early and late productive seasons (Oct-Dec and Jan-Apr, respectively) are based on KRILLBASE data, overwintering (May-Sep) on CCAMLR data. Note that the relative lack of individuals below $35 \mathrm{~mm}$ during winter is most likely a result of undersampling by the coarse meshes used by fishery vessels. Data were smoothed using a moving average algorithm. TL: total body length
(1987). Accordingly, mode 2 contains $2+$ individuals and mode 3, 3+ individuals. Although older krill (4+ and 5+) probably occur within the population, their contribution could not be distinguished through the present component-fitting analysis.

\section{Comparative structure of males and females}

There was a clear difference in the body-length frequencies of the female and male populations over the seasonal cycle (Fig. 5). In the early and late productive seasons, females were more numerous than males in most of the comparable size classes at $>35 \mathrm{~mm}$. However, the frequencies of both sexes were similar in all size-class intervals above $50 \mathrm{~mm}$. Over the winter, the distribution above $50 \mathrm{~mm}$ was strikingly different to other seasons, with males being consistently more abundant than females.

The seasonal shift in the relative proportions of males and females is further illustrated when considering sex ratio (PM) per size interval (Fig. 6). Both the KRILLBASE summer and CCAMLR summer databases show that PM is at or below 0.5, with the lowest values found above $55 \mathrm{~mm}$. Notable is the offset of around 0.1 between these 2 databases, illustrating a $10 \%$ shift in sex ratio in favour of females in the CCAMLR summer dataset, most likely a result of a summer bias towards females in the commercial

Table 1. Euphausia superba. The best-fitting components within adult female and adult male body-length frequency distributions in the early productive season (Oct-Dec), late productive season (Jan-Apr) and overwintering (May-Sep) in the Scotia-Weddell region. Values represent the point of the modal peak (SD) and \% of the population. Note that the distributions are log-normal. Italics denotes that the value was not used when fitting seasonally modulated von Bertalanffy functions

\begin{tabular}{|lccc|}
\hline & Oct-Dec & Jan-Apr & May-Sep \\
\hline Female & & & \\
Mode 1 & $32.26(4.61)$ & $39.58(5.00)$ & $35.34(3.72)$ \\
& $51.70 \%$ & $53.30 \%$ & $30.60 \%$ \\
Mode 2 & $41.85(4.26)$ & $46.12(2.88)$ & $42.80(3.95)$ \\
& $36.90 \%$ & $25.60 \%$ & $46.60 \%$ \\
Mode 3 & $48.54(3.29)$ & $51.08(3.49)$ & $47.28(3.15)$ \\
& $11.40 \%$ & $21.10 \%$ & $22.90 \%$ \\
Male & & & \\
Mode 1 & $32.91(4.68)$ & $36.35(4.73)$ & $36.27(3.93)$ \\
& $54.50 \%$ & $23.00 \%$ & $21.20 \%$ \\
Mode 2 & $44.08(4.13)$ & $44.02(3.82)$ & $44.11(3.82)$ \\
& $37.70 \%$ & $35.70 \%$ & $50.00 \%$ \\
Mode 3 & $50.47(2.90)$ & $49.53(2.78)$ & $50.01(3.35)$ \\
& $7.70 \%$ & $41.40 \%$ & $28.80 \%$ \\
\hline
\end{tabular}



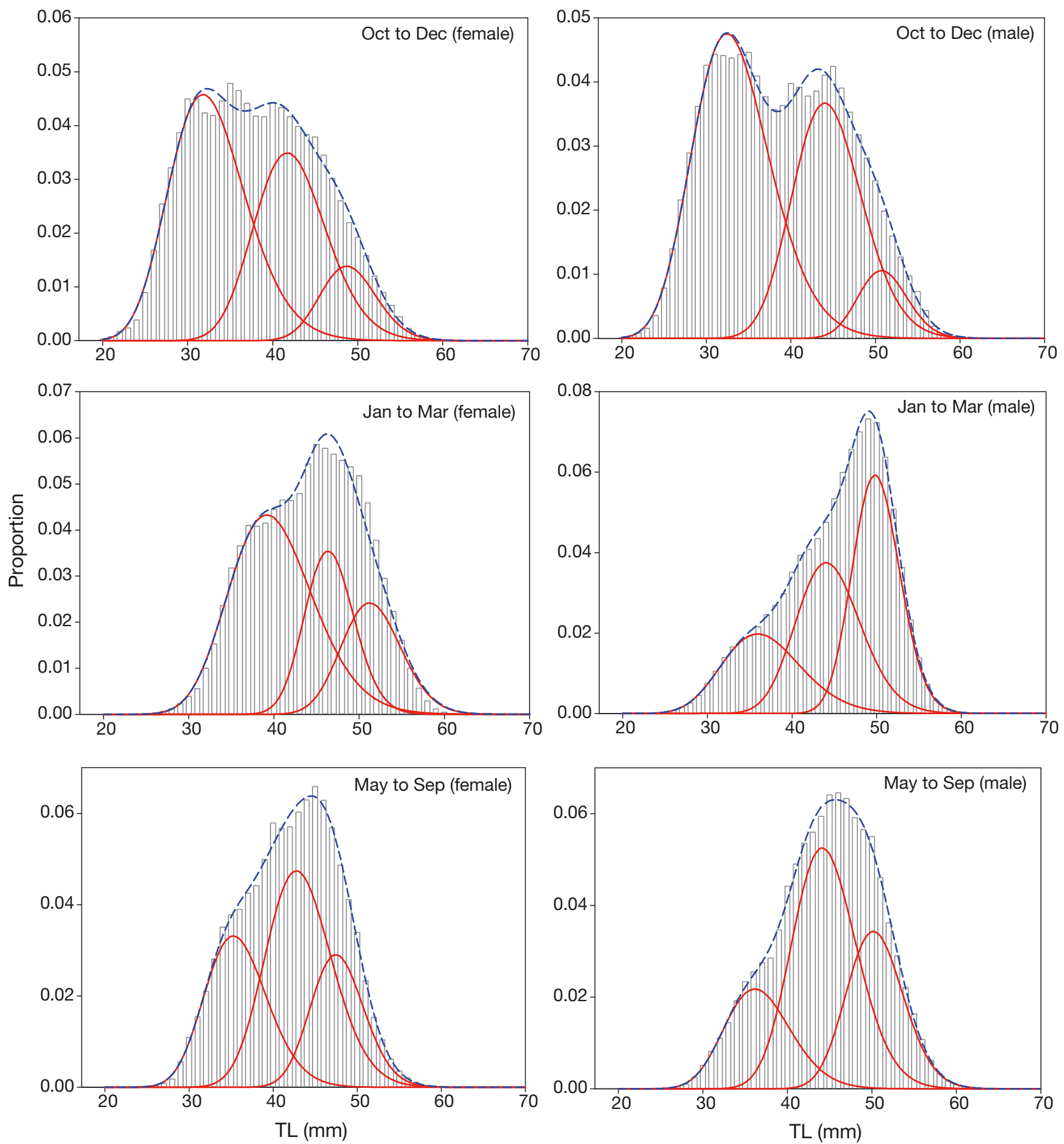

Fig. 4. Euphausia superba. Best component fits (red lines) to body-length frequency distributions (blue dashed line) of females (left) and males (right) during the early productive season (Oct-Dec; upper), late productive-season (Jan-Apr; middle) and overwintering (May-Sep; lower) in the Scotia-Weddell region. Early and late productive seasons are based on KRILLBASE data, overwintering on CCAMLR data. TL: total body length

fishery. Females were similarly dominant in the CCAMLR winter dataset below $50 \mathrm{~mm}$, but, above this body length, the sex ratio became increasingly male dominated to the extent that more than $80 \%$ of all krill above $55 \mathrm{~mm}$ were males. Median PM across all body-length classes was 0.44 in the early produc- tive season, 0.46 in the late productive season and 0.41 in the overwintering period. The increase in the $\mathrm{PM}$ of large adults during winter can therefore not be explained by greater wintertime mortality in females, which, in fact, increased as a proportion of the population during that time. 


\section{Sexual regression}

During winter, individuals with an external juvenile appearance occurred at almost all body-length intervals (Fig. 3). This indicates a regression of some adults to a juvenile state during the overwintering period (Siegel 2012), although it must also be noted that the level of expertise of fishery observers most
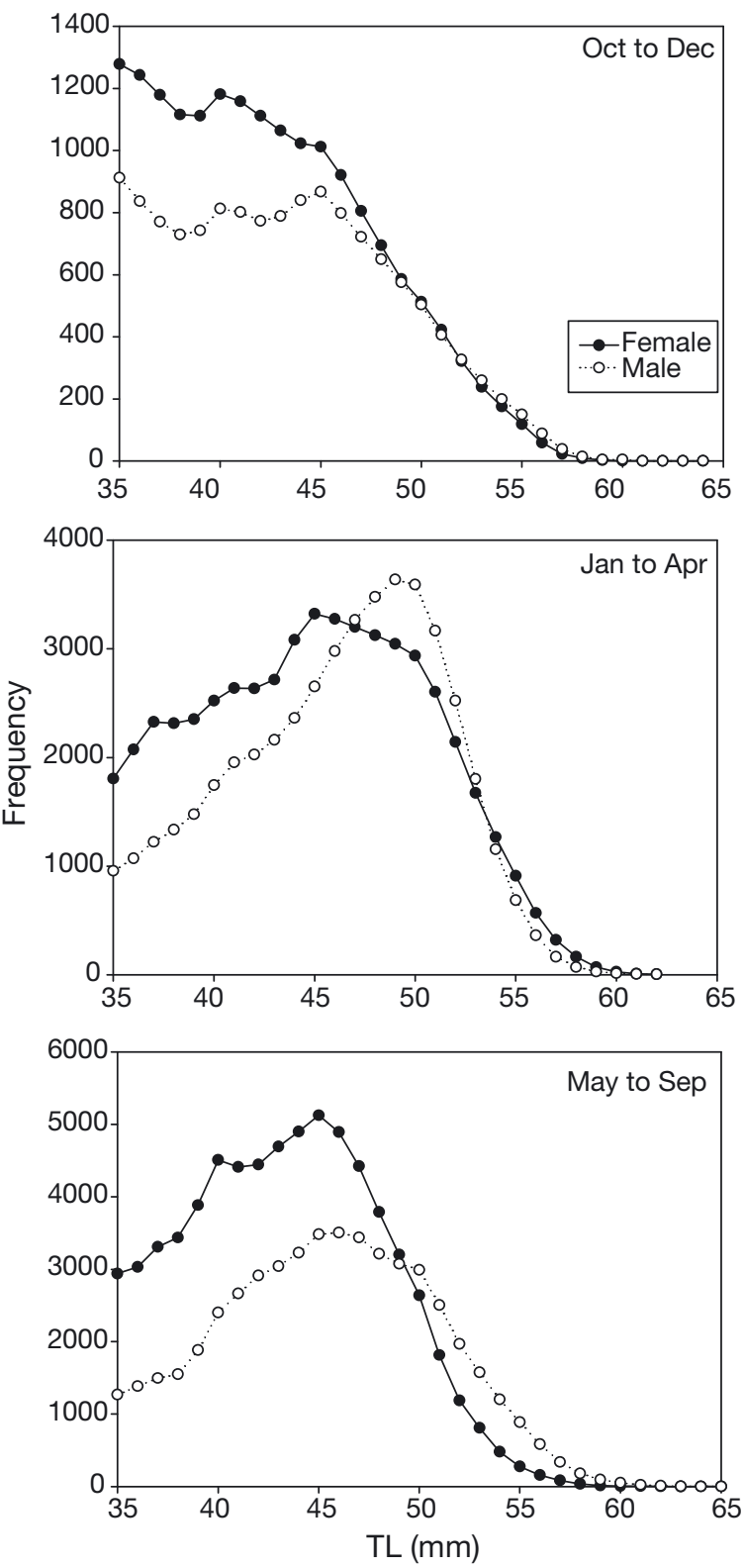

Fig. 5. Euphausia superba. Comparison of female and male body-length frequency distributions ( $\geq 35 \mathrm{~mm}$ total body length) during the early productive season (Oct-Dec), late productive season (Jan-Apr) and overwintering (May-Sep) in the Scotia-Weddell region. Early and late productive seasons are based on KRILLBASE data, overwintering on CCAMLR data. TL: total body length likely varied between cruises and there is the potential for some misclassification of such regression. Sensitivity analyses showed that sex-related skew in the proportion of adult regression to a juvenile external appearance (either through genuine or misclassified sexual-regression) had the potential to explain the relatively low PM values observed in the smaller size classes (Fig. 7). In a scenario where all the juve-

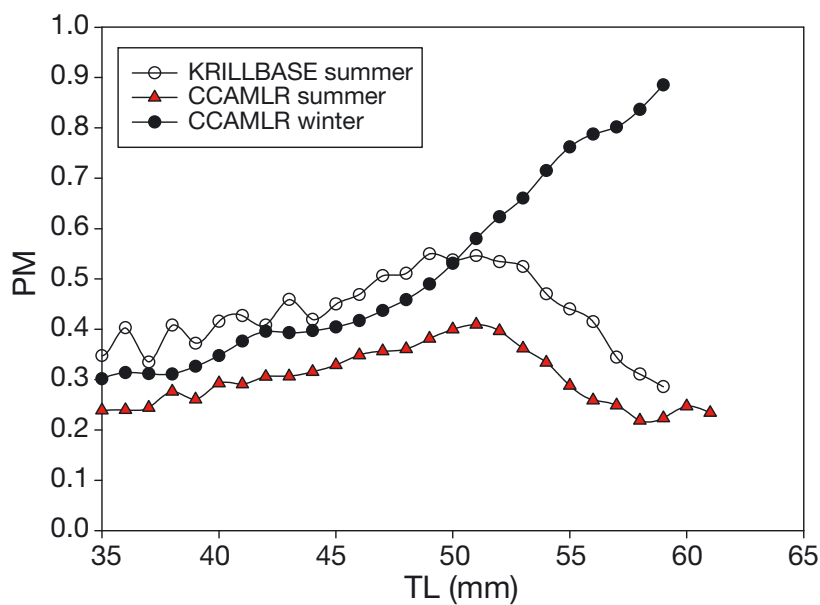

Fig. 6. Euphausia superba. Proportion of males (PM) as a function of total body length $(\geq 35 \mathrm{~mm})$ in the adult population of the Scotia-Weddell region according to KRILLBASE during summer (Oct-Apr), the CCAMLR dataset during summer (Oct-Apr) and the CCAMLR dataset during overwintering (May-Sep). PM was calculated as the sum of males per interval divided by the sum of males and females per interval



Fig. 7. Euphausia superba. Sensitivity analysis illustrating the effect of the proportion of adult regression to a juvenile appearance on the proportion of males (PM) as a function of total body length ( $\geq 35 \mathrm{~mm}$ ) during the overwintering period (May-Sep) in the Scotia-Weddell region. TL: total body length; F: female; M: male 
niles between 35 and $40 \mathrm{~mm}$ consisted of 10 to $25 \%$ ex-females and 75 to $90 \%$ ex-males, the overwintering PM values (0.26 to 0.33 ) would be equivalent to those observed during summer. However, no scenario could explain the difference between late productive season and winter PM values in size classes above $50 \mathrm{~mm}$. The sensitivity analysis therefore indicates that the skew towards males in these larger size classes during the overwintering period was not a result of the greater level of genuine or misclassified regression to a juvenile state in females.

\section{Inter-regional comparison}

As well as the Scotia-Weddell region, the fishery for Antarctic krill also operates at South Georgia and the WAP. During overwintering in both of those locations there was an offset between the size distribution of females and males that resembled that observed in the Scotia-Weddell region (Fig. 8). In particular, a much higher proportion of males than females were found in size classes above $50 \mathrm{~mm}$. This was also reflected in the comparison of PM distributions, where there was a continual increase in PM with increasing body length, particularly above $50 \mathrm{~mm}$ (Fig. 9). In the WAP, the maximum PM was around 0.6, whereas at South Georgia, as well as in the Scotia-Weddell region, PM reached a maximum of 0.9 in the largest size classes.

\section{Growth trajectories}

In both sexes, sVBFs were found to obtain better fits to the observed data when fitted to the smaller and larger body lengths separately (Table 2), which suggests that the characteristic oscillations in growth alter over the course of adult life. Furthermore, the nature of these oscillations in growth differed between the sexes. Male body-length growth was rapid in the early productive season and then stagnated for the remainder of the year, while female body-length growth occurred later in the year and was followed by a period of shrinkage. We found that male growth was best simulated by a switched-growth sVBF, whereas female growth was better represented by a sine-wave growth sVBF (Fig. 10). Despite the differences in growth characteristics, both males and females reach the same average 4 -yr-old adult size of $\sim 50 \mathrm{~mm}$. However, whereas the male modal peak remains at $50 \mathrm{~mm}$ during overwintering, the female modal peak decreases to $47 \mathrm{~mm}$ before returning to


Fig. 8. Euphausia superba. Comparison of female and male body-length frequency distributions ( $\geq 35 \mathrm{~mm}$ total body length) during overwintering (May-Sep) at South Georgia (upper) and in the Western Antarctic Peninsula (lower). TL: total body length

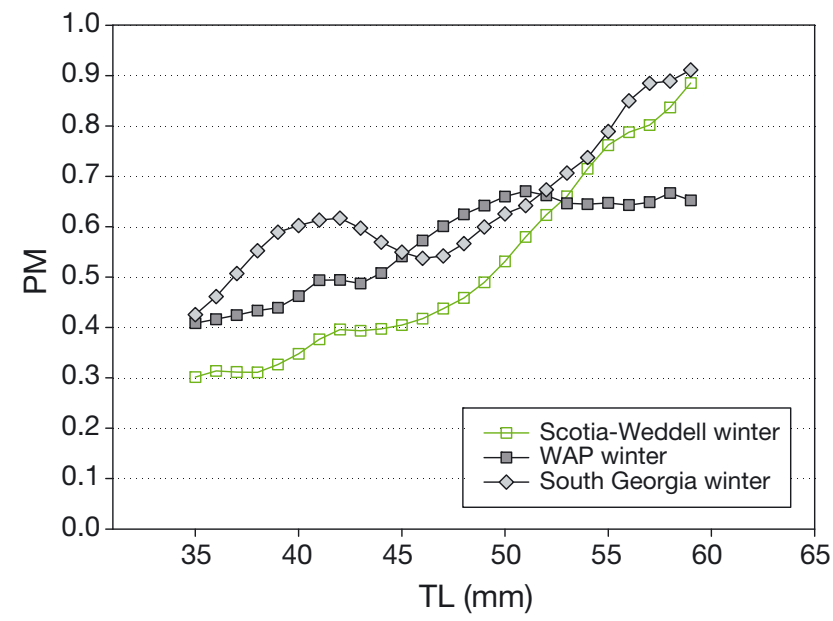

Fig. 9. Euphausia superba. Proportion of males (PM) as a function of total body length $(\geq 35 \mathrm{~mm})$ in the adult population during the overwintering period in the Scotia-Weddell region, the Western Antarctic Peninsula (WAP) and South Georgia. TL: total body length 
Table 2. Optimal parameter fits of seasonally modulated von Bertalanffy functions (sVBF) fitted to modal peaks identified within seasonally resolved body-length frequency distributions of female and male Antarctic krill in the Scotia-Weddell Sea region. Female growth was fitted by a sine-wave sVBF function, $L_{\mathrm{t}}=L_{\text {inf }}\left(1-\mathrm{e}^{-K}\right)$, where $K=C \sin \left(\frac{2 \pi(t-s)}{52}\right)+K\left(t-t_{0}\right)$. Male growth was fitted by a switched-growth sVBF function, $L_{\mathrm{t}}=L_{\text {inf }}\left(1-\mathrm{e}^{-K(\operatorname{tg}-t 0)}\right)$, where $\frac{\mathrm{d} t_{g}}{\mathrm{~d} t_{s}}=0$ when $\cos =\left(\frac{2 \pi t_{s}}{52}\right)<s w$. The split point (week/month/year after spawn) refers to the point at which the observed dataset was split into a younger and older section. The sVBF was fitted to each of the 2 sections separately. $C$ is a constant, sw: time spent growing each year, $t_{0}$ : time from which the growth-curve starts, $K$ : the rate parameter, $s$ : time at which zero growth begins and ends (switchedgrowth function) or starting point for the sine (sine-wave growth function), $L_{\text {inf }}$ maximum total body length (mm). Supplement 3 contains a more detailed explanation of the functions and the split points

\begin{tabular}{|lccccccc|}
\hline & $C$ & $S W$ & $t_{0}$ & $K$ & \multicolumn{1}{c}{$S$} & $L_{\text {inf }}(\mathrm{mm})$ & Split time point \\
\hline Females & & & & & & & \\
Younger modes & 0.157042 & - & -74.048 & 0.005976 & -6.96 & 65 & 1 st week of July, year 2+ \\
Older modes & 0.162127 & - & -101.398 & 0.005296 & -10.73 & 65 & \\
Males & - & -0.100 & -24.2307 & 0.010499 & -10.00 & 65 & 1 1st week of July, year 3+ \\
Younger modes & - & 0.100 & -5.9820 & 0.013420 & -16.00 & 65 & \\
Older modes & - & & & & & & \\
\hline
\end{tabular}

growth during the late overwintering period and the early productive season.

According to the fitted growth rate trajectories, average adult growth rates during the early productive season varied between +0.020 and $+0.103 \mathrm{~mm}$ $\mathrm{d}^{-1}$, with higher rates occurring in younger adults (Table 3). During the late productive season, growth

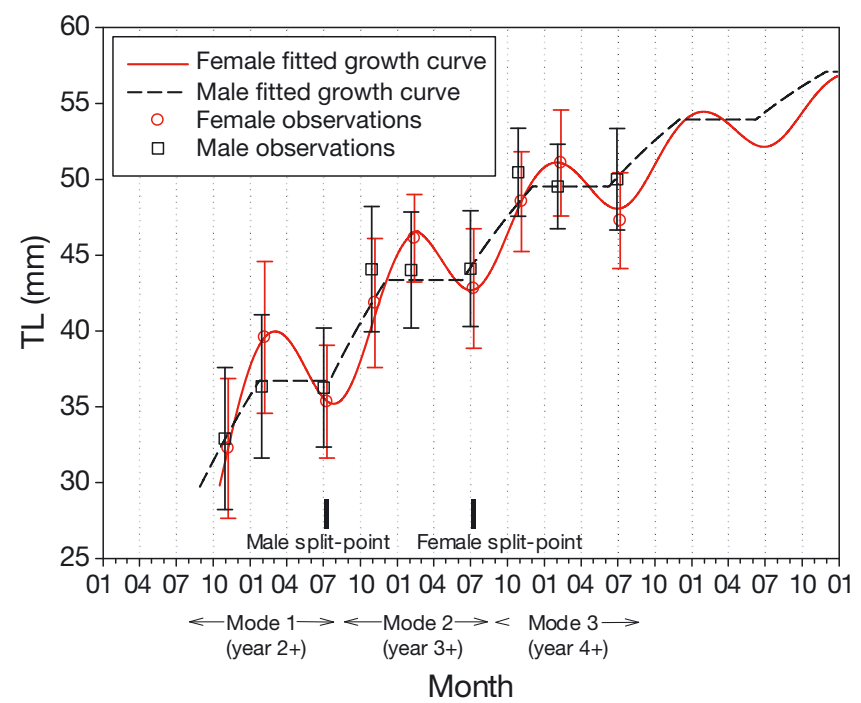

Fig. 10. Euphausia superba. Best fits of seasonally adjusted von Bertalanffy growth functions (lines) to modal peaks (symbols) in the Scotia-Weddell adult population. Separate fits were made to the females and males, the former using a sine-wave growth function, the latter, a switched-growth function. In each instance, the datasets were divided into smaller and larger body length fractions and a function fitted to each fraction separately. The body length at which the split was made was part of the fitting procedure and is indicated for each sex. TL: total body length. Error bars denote $\pm 1 \mathrm{SD}$ rates had already become comparatively reduced, with the maximum rate being $+0.044 \mathrm{~mm} \mathrm{~d}^{-1}$ in mode 1 males. Older male year classes had already entered the period of growth stagnation during this period. In females, this period may also include some bodylength shrinkage (minimum growth rates of between -0.031 and $-0.046 \mathrm{~mm} \mathrm{~d}^{-1}$ ). Growth resumed by the end of winter, such that average growth rates for this period were mainly positive in both males and females.

The seasonal shape of the fitted curves indicated that the highest growth rates occurred in the early productive season and growth recommenced even within the latter part of the overwintering period. This was especially true of males, which had average growth rates of between 0.01 and $0.03 \mathrm{~mm} \mathrm{~d}^{-1}$ during overwintering, mainly as a result of growth during the latter part of this period. By the early productive period, average growth rates reached up to $0.05 \mathrm{~mm}$ $\mathrm{d}^{-1}$. Females showed little growth during overwintering, but had higher average growth rates than males during the early productive period, ranging between 0.05 and $0.1 \mathrm{~mm} \mathrm{~d}^{-1}$.

\section{Body length to age relationships}

The differences between males and females in growth trajectories also mean that there were differences between sexes with respect to the relationship between body length and age. Component-fitting analyses identified modes that peaked at different body lengths in females compared with males. In particular, during the late productive season, females 
Table 3. Euphausia superba. Rates of growth in body length $\left(\mathrm{mm} \mathrm{d}^{-1}\right)$ over the adult life cycle in the Scotia-Weddell region, as estimated by seasonally adjusted von Bertalanffy functions fitted to modal peaks identified in body-length frequency distributions. Negative values denote shrinkage in body length. Early productive season: October to December; late productive season: January to April; overwintering: May to September

\begin{tabular}{|c|c|c|c|c|c|c|}
\hline & \multicolumn{2}{|c|}{ Maximum growth rate } & \multicolumn{2}{|c|}{ Minimum growth rate } & \multicolumn{2}{|c|}{ Mean (SD) growth rate } \\
\hline & Female & Male & Female & Male & Female & Male \\
\hline Mode 1, Early productive season & 0.1167 & 0.0499 & 0.0764 & 0.0440 & $0.1033(0.0142)$ & 0.0469 (0.0019) \\
\hline Mode 1, Late productive season & 0.0684 & 0.0436 & -0.0457 & 0.0000 & $0.0052(0.0374)$ & $0.0076(0.0169)$ \\
\hline Mode 1, Overwintering & 0.0750 & 0.0539 & -0.0509 & 0.0000 & $-0.0020(0.0449)$ & $0.0252(0.0259)$ \\
\hline Mode 2, Early productive season & 0.0855 & 0.0465 & 0.0560 & 0.0000 & $0.0765(0.0097)$ & $0.0305(0.0212)$ \\
\hline Mode 2, Late productive season & 0.0501 & 0.0000 & -0.0413 & 0.0000 & $-0.0082(0.0342)$ & $0.0000(0.0000)$ \\
\hline Mode 2, Overwintering & 0.0640 & 0.0412 & -0.0386 & 0.0000 & $0.0161(0.0365)$ & $0.0284(0.0164)$ \\
\hline Mode 3, Early productive season & 0.0642 & 0.0332 & 0.0191 & 0.0000 & $0.0461(0.0153)$ & $0.0203(0.0157)$ \\
\hline Mode 3, Late productive season & 0.0143 & 0.0000 & -0.0314 & 0.0000 & $-0.0155(0.0155)$ & $0.0000(0.0000)$ \\
\hline Mode 3, Overwintering & 0.0487 & 0.0294 & -0.0293 & 0.0000 & $0.0139(0.0281)$ & $0.0205(0.0115)$ \\
\hline
\end{tabular}

were longer than males by $3 \mathrm{~mm}$ in mode 1 and $2 \mathrm{~mm}$ in mode 2. By the overwintering period, these differences reduced to approximately $1 \mathrm{~mm}$. The pattern was different in mode 3, where, although the modal peaks in the productive season were the same, those during overwintering were $3 \mathrm{~mm}$ shorter in females than in males. Furthermore, the overwintering modal peak was $4 \mathrm{~mm}$ shorter than that in the late productive season in females, whereas that in the males was $0.5 \mathrm{~mm}$ longer.

\section{Validation: simulation of overwintering population}

Simulations of overwintering size structure focused on females given that total body length of males was found to remain relatively constant during this period. In accordance with the fitted $\mathrm{sVBF}$, the $R_{\mathrm{t}}$ growth factor was set at $-4 \mathrm{~mm}$ for mode 1 females, $-3.5 \mathrm{~mm}$ for mode 2 females and $-4 \mathrm{~mm}$ for mode 3 females. The simulated size structure closely resembled that observed during the overwintering period, particularly between 41 and $60 \mathrm{~mm}$ total body length (Fig. 11). Peak female size class was estimated to be $45 \mathrm{~mm}$ in both the simulated and observed overwintering size distributions. Nevertheless, the simulation overestimated the proportion of females observed between 35 and $40 \mathrm{~mm}$ by up to $3 \%$ per size class, suggesting that estimated growth and shrinkage factors were less robust in these body-length classes.

\section{DISCUSSION}

The present study performed population dynamic analyses on the 2 most comprehensive Antarctic krill body-length datasets yet amassed, covering the Scotia-Weddell region, the WAP and South Georgia, with more than 686000 measured individuals over 49 yr. A distinguishing feature of this study is the inclusion of a substantial body of CCAMLR fishery data from winter, a period that has been poorly sampled by scientific surveys. The outcomes of the analyses are complex to interpret, which is, in part, the consequence of methodological issues within each database. Nevertheless, a clear dominance of males in the upper body-length range of overwintering krill stands out as a robust and widespread pattern across all analyses. This reflects a consistent reduction in body length of all the female cohorts by mid-winter, while the body lengths of male cohorts appear to

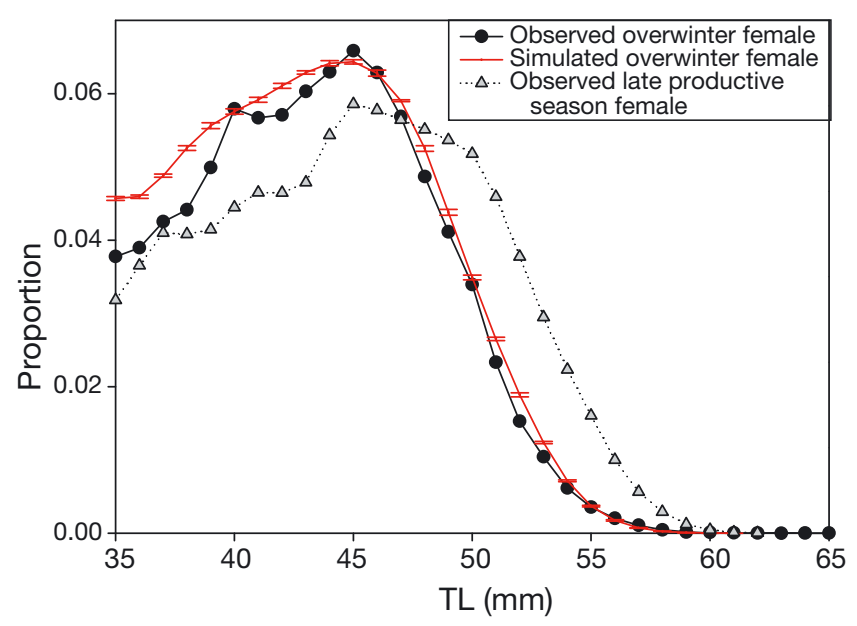

Fig. 11. Euphausia superba. Comparison of simulated and observed female body-length frequency distributions ( $\geq 35 \mathrm{~mm}$ total body length) between the late productive season and overwintering in the Scotia-Weddell region. Simulated overwintering data were derived through applying a growth/shrinkage factor (derived from the fitted seasonally adjusted von Bertalanffy growth function) to observed late productive season data. Late productive season observations are based on KRILLBASE data, overwintering observations on CCAMLR data. TL; total body length. Error bars denote $\pm 1 \mathrm{SD}$ 
remain the same during this time. We conclude that the most likely scenario is an autumn-winter contraction in body length of the mature females. In subsequent sections, we will discuss a number of other candidate explanations for these results, and describe how each fails as an alternative explanation.

\section{Comparison of data sources}

Our use of datasets from CCAMLR has allowed us to resolve the Antarctic krill life cycle across the complete annual cycle. It is nevertheless a set of data that has been collected in a different way to that obtained through the scientific survey methods within KRILLBASE. Fishery nets have a coarser mesh so are unlikely to sample smaller size classes in a representative manner. We found that the population structure in the CCAMLR and KRILLBASE databases diverged at around $35 \mathrm{~mm}$, with specimens smaller than this size being under-represented in the CCAMLR dataset. Fishery nets are also comparatively large and are sampled at faster speeds, which probably results in less avoidance by larger, more mobile krill (Jones \& Ramm 2004). This may be a factor explaining the slightly greater proportion of larger krill in CCAMLR summer catches compared with those in the KRILLBASE datasets. There is also a potential bias in the way fishery trawls are targeted, which reflects a historical preference for catches containing gravid females (Kawaguchi et al. 2005, Kawaguchi \& Nicol 2007). We found that the CCAMLR summer data, on average, contained $10 \%$ more females than KRILLBASE. Fishing industry sources suggest that some vessels avoid green krill (i.e. those that contain undigested phytoplankton) and high-density aggregations of krill, although the implications this has to the sampled population structure is difficult to ascertain.

With prior knowledge of potential biases, our analyses were performed to accommodate these issues when comparing between KRILLBASE and CCAMLR datasets. For instance, the first component in the winter population structure was not considered when fitting growth curves, given that this part of the population was under-sampled in the CCAMLR datasets. Furthermore, our conclusion of female bodylength shrinkage was based on several different lines of evidence, so as to reduce the reliance on any single perspective. Particularly useful in this regard was the comparison of the growth characteristics of males and females. Whereas the female modal peaks all occurred at smaller body lengths in winter compared with summer, the male peaks all remained approxi- mately the same. This allowed the males to act as a control for sampling error between seasons. Furthermore, we repeatedly cross-referenced body-length frequency and sex-ratio patterns obtained from the KRILLBASE datasets with those from the summer CCAMLR datasets to check for consistency and identify any methodological biases.

\section{Trajectories of growth and shrinkage in body length}

In fitting the sVBFs to the Scotia-Weddell data, we found that male growth was best characterised by the switch-growth function because it captured alternating periods of positive growth and then zero growth apparent from the component-fitting analysis. The period during which growth stagnated started within the late production season, especially in the older modes. Female growth was better described by a sine-wave growth function, because componentfitting analysis identified periods of alternating growth and shrinkage in body length. During the winter period, females shrank by up to $75 \%$ of the body length they had gained the previous summer. In mode 2, this meant that overwintering females were approximately the same body length as males (43 to $44 \mathrm{~mm}$ ), whereas, in mode 3 , overwintering females were, on average, $3 \mathrm{~mm}$ shorter than males.

Using the instantaneous growth rate (IGR) approach, Kawaguchi et al. (2006) found a similar pattern of highest growth in body length earlier in the productive season. In the SW Atlantic sector (an area encompassing both the Scotia-Weddell and South Georgia sectors in the present study), they found that growth rates in November and December were mainly between 0.20 and $0.30 \mathrm{~mm} \mathrm{~d}^{-1}$, whereas later in the year they were between 0.05 and $0.15 \mathrm{~mm} \mathrm{~d}^{-1}$. From body-length frequency distributions within furseal stomachs at South Georgia, Reid (2001) proposed that the main period of growth in body length was from September to December, and that little growth occurred beyond January. Other studies have shown that rapid growth phases appear to occur later in the season in the WAP (Siegel 1986) and in the Indian sector (Kawaguchi et al. 2006), which is likely to reflect the later start to the bloom periods in those regions (Kawaguchi et al. 2006). For instance, using kernel-density analysis, Shelton et al. (2013) found that the most common growth rates at Elephant Island (within the Scotia-Weddell region) in January and February were between 0.05 and $0.1 \mathrm{~mm} \mathrm{~d}^{-1}$, equivalent to the rates we observed earlier in the year in the Scotia-Weddell region. 
In females, the fitted sVBF curve predicted a period of body-length shrinkage just before and into the winter period. Maximum shrinkage rates (minimum growth rates) varied between -0.051 and $-0.031 \mathrm{~mm}$ $\mathrm{d}^{-1}$ between modes, with mode 1 females exhibiting the greatest rates of shrinkage (Table 3). Candy \& Kawaguchi (2006) fitted a number of different types of sVBFs to an extensive set of IGR data. There were no IGR data available for the overwintering period, so growth rates over that time were inferred. They found that a scenario that allowed for an overwintering shrinkage rate of $1.5 \%$ per moult $(-0.034$ to $-0.011 \mathrm{~mm} \mathrm{~d}^{-1}$, assuming an intermoult period of between 20 and $60 \mathrm{~d}$ for a $45 \mathrm{~mm}$ adult) produced the best fit to observed body lengths. In the only overwintering Antarctic krill IGR study yet carried out, Quetin \& Ross (1991) calculated body-length shrinkage rates of krill in the WAP of between 0.16 and $2.03 \%$ per moult, and intermoult periods of 30 to $60 \mathrm{~d}$, giving a range of -0.001 to $-0.030 \mathrm{~mm} \mathrm{~d}^{-1}$ (for a $45 \mathrm{~mm}$ adult). Our fitted shrinkage rates are therefore towards, but not outside of, the upper range of those estimated by other studies.

\section{Influences on sex-ratio patterns}

Our undertaking to analyse patterns over large spatial and temporal scales was in part motivated by a need to minimise the influence of immigration and emigration in our analyses. Analysing datasets at these spatial and temporal scales also overcomes the further issue of identifying each major cohort despite interannual variations in levels of recruitment. Variation in both migration and recruitment may result in a modal class being absent, leading to the erroneous assessment of growth and development. For similar reasons, we also undertook a comparison with the situation found in 2 other large-scale regions, the WAP and South Georgia. In all 3 regions, we found that females comprised a considerably smaller portion of the overwinter population greater than $50 \mathrm{~mm}$ body length compared with males.

One explanation for this skew in sex ratio during overwintering is that there is a sexual difference in the relationship between body length and mortality, with males suffering higher mortality at smaller body lengths (i.e. younger ages) and females at larger body lengths (i.e. at an older age). However, there are 2 lines of evidence against this interpretation. Firstly, the sex-ratio trajectory (represented as the proportion of males, PM, per body-length increment) was comparatively flat during the productive season, with the majority of body-length increments exhibiting PM values between 0.4 and 0.6 . This contrasts with the overwintering situation of an upward trajectory in PM, reaching 0.9 above $50 \mathrm{~mm}$. The lack of sex-ratio bias in summer appears contrary to an explanation that relies on a severe depletion in numbers of one sex. Secondly, median PM values across all length classes were $0.41,0.44$ and 0.46 during overwintering, early and late productive seasons, respectively. Therefore, if anything, females made up a greater proportion of the population during overwintering.

Alternatively, the overwintering skew in PM could be the result of a seasonal spatial or vertical segregation of male and females. Spatially, Siegel (1987, 2000) suggested that adults move offshore in order to spawn during summer. Even if this tendency was more likely to occur in females than in males, the CCAMLR and KRILLBASE databases contain catches from both onshore and offshore environments. Whether one sex is more likely to migrate beneath the sea-ice is unknown, and cannot be directly addressed with current technology, although net surveys have suggested that juveniles and sub-adults are more likely to inhabit under-ice environments than adults (Cuzin-Roudy \& Schalk 1988). Vertically, krill are known to make deep migrations to the sea bed (Clarke \& Tyler 2008), a behaviour that may potentially be more prevalent in one sex than the other. However, observations to date have shown that such deep migrations are undertaken by both sexes with little indication of any sex bias (Schmidt et al. 2011).

Another potential influence on PM is the regression of sexual characteristics during overwintering, which results in individuals that have already bred and subsequently regressed being recorded as juveniles. Juveniles occurred at almost all body-length increments during overwintering, which is a strong indication that a proportion of even the larger adults had regressed. What is not known is whether one sex is more likely to regress than the other. Our results did not provide any further direct evidence of this, so instead we carried out a sensitivity analysis to determine whether the observed skews in PM could be explained by a sex-based bias in genuine or misclassified sexual regression. We found that regression could account for PM skew in the smaller body-length classes, but could not explain the strong skew towards males above $50 \mathrm{~mm}$. There is no possibility that adults may change sex between seasons, given observations of germinal zones (oogonia and spermatogonia) being present year-round (Cuzin-Roudy 1987).

Overall, in explaining our observation of the relative lack of females in size classes above $50 \mathrm{~mm}$ 
during winter, we have ruled out the following major influences: (1) the migration of stocks, given the comprehensive spatial scale of our datasets; (2) sexselective mortality, as males do not make up a higher proportion of the overall adult population during overwintering; (3) sexually differentiated seasonal vertical migration, given that sex bias has not been reported in records of deep stocks; and (4) sex-based bias in the regression of secondary sexual characteristics because our sensitivity analyses show that this cannot account for the observed dramatic changes in sex ratio. This leaves differential growth and shrinkage in body length between sexes as the remaining explanation for this skew. We validated this explanation through successfully simulating overwinter size structure from late-productive size structure using the shrinkage factor derived by this study. The simulations involved applying cohort-specific shrinkage factors, derived from sVBFs, that were between 3 and $4 \mathrm{~mm}$, depending on the mode. Our ability to achieve a close congruence between predicted and observed overwinter population structures by this means indicates that shrinkage in female body length is an adequate and sufficient explanation for the skew in sex ratio in the older size classes of the population during overwintering.

\section{Significance of body-length shrinkage}

Seasonal changes in the length of krill are important in terms of both krill ecophysiology and interpreting stock structure for fisheries management. In the present analysis, we found that shrinkage in body length during winter was most likely to occur in females. Male and female Antarctic krill show a clear dimorphism in body shape (Farber-Lorda 1990), which is most notable in the relative sizes of the cephalothorax. In females, this body section contains the ovaries and the 'fat body', which can make up to $40 \%$ of total individual wet mass in fully gravid individuals (Tarling et al. 2007). Accordingly, the cephalothorax can be more than $30 \%$ longer in females compared with males of similar total body length (Goebel et al. 2007). The ovaries and the fatbody regress at the end of the productive season (Cuzin-Roudy \& Amsler 1991, Cuzin-Roudy 1993). Without the need to contain this large mass, the cephalothorax itself reduces in size, with a corresponding reduction in total body length. A useful test of this hypothesis would be to compare carapace with total body-length measurements in females from productive and overwintering seasons, which can be achieved through minor modifications to the fishery observer krill measurement protocol.

Our finding that Antarctic krill are capable of decreasing in body length is consistent with laboratory studies on a number of euphausiid species (Euphausia pacifica, Lasker 1966; E. superba, Ikeda \& Dixon 1982; Meganyctiphanes norvegica, Buchholz 1985; Thysanoessa inermis, Dalpadado \& Ikeda 1989; and Nyctiphanes australis, Hosie \& Ritz 1989). These studies mainly incubated individuals in suboptimal conditions, particularly with regards to the availability of food. The question that has remained is how frequently (if ever) krill field populations encounter food shortage sufficient to engender bodylength shrinkage and do they do so for sufficient periods to affect the size structure of the population (Nicol 2000)?

In a study of stomach contents and body reserves, Schmidt et al. (2014) contended that krill experienced varying levels of overwintering hardship, with those in the WAP and Scotia-Weddell region faring better as a result of longer phytoplankton blooms and access to benthic food compared with those in the deep, seasonally ice-covered Lazarev Sea. It follows that our observations of female body-length shrinkage occurs even in some of the best overwintering conditions for Antarctic krill. This suggests that body-length shrinkage alone may not necessarily signify winter hardship. Instead, a summer increase and winter contraction in body length in female krill may reflect stages in their sexual development: from pre-spawn vitellogenesis for egg production during spring and summer to post-spawn ovary and fat-body regression in the overwintering period (Cuzin-Roudy \& Amsler 1991, Cuzin-Roudy 1993). The fact that non-regressed males do not shrink during winter also argues against body-length shrinkage being solely the result of starvation in natural populations.

\section{Implications for future management}

Future management of the Antarctic krill fishery makes use of population projections to evaluate potential management options (Miller \& Agnew 2000). CCAMLR is working to improve this management system and it is likely that assessment and projection models will play central roles in the future management of the fishery (Hill \& Cannon 2013, Kinzey et al. 2015). Any such model may produce erroneous results if assumptions about growth are incorrect. The models developed on behalf of CCAMLR have generally been careful to account 
for uncertainties, including variability in plausible growth rates. Our finding of body-length shrinkage in field populations of Antarctic krill implies a need to extend this consideration to incorporate negative rates of growth in body length.

Acknowledgements. We are particularly grateful to Evgeny Pakhomov, Volker Siegel and Valerie Loeb, who provided considerable amounts of data to the KRILLBASE database. Other data providers are included in Supplement 1, to whom we extend our thanks. Much of the original construction of the KRILLBASE length frequency database was carried out by Mark Jessopp. Steve Candy supplied valuable input on projecting sex ratio under different scenarios of mortality and lifespan. Eugene Murphy contributed helpful discussions on growth trajectories. George Watters made constructive criticisms on earlier drafts of the manuscript. The CCAMLR data was provided by the CCAMLR data centre (Hobart, Tasmania) and has been published in accordance with the rules adopted by the Twenty-Second Meeting of the Commission (CCAMLR-XXII, paragraphs 12.1 to 12.6).

\section{LITERATURE CITED}

Atkinson A, Shreeve RS, Hirst AG, Rothery P and others (2006) Natural growth rates in Antarctic krill (Euphausia superba): II. Predictive models based on food, temperature, body length, sex, and maturity stage. Limnol Oceanogr 51:973-987

Atkinson A, Siegel V, Pakhomov EA, Rothery P and others (2008) Oceanic circumpolar habitats of Antarctic krill. Mar Ecol Prog Ser 362:1-23

Atkinson A, Siegel V, Pakhomov EA, Jessopp MJ, Loeb V (2009) A re-appraisal of the total biomass and annual production of Antarctic krill. Deep-Sea Res I 56:727-740

Bargmann HE (1945) The development and life history of adolescent and adult krill, Euphausia superba. Discov Rep 23:103-176

Buchholz F (1985) Moult and growth in Antarctic euphausiids. In: Siegfried WR, Condy PR, Laws RM (eds) Antarctic nutrient cycles and food webs. Springer-Verlag Berlin, p 339-345

Candy SG, Kawaguchi S (2006) Modelling growth of Antarctic krill. II. Novel approach to describing the growth trajectory. Mar Ecol Prog Ser 306:17-30

Clarke A (1984) Lipid content and composition of Antarctic krill, Euphausia superba Dana. J Crustac Biol 4:285-294

> Clarke A, Tyler PA (2008) Adult Antarctic krill feeding at abyssal depths. Curr Biol 18:282-285

Constable AJ, de la Mare WK (1996) A generalised model for evaluating yield and the long-term status of fish stocks under conditions of uncertainty. CCAMLR Sci 3: $31-54$

> Croxall JP, Nicol S (2004) Management of Southern Ocean fisheries: global forces and future sustainability. Antarct Sci 16:569-584

> Cuzin-Roudy J (1987) Sexual differentiation in the Antarctic krill Euphausia superba (Crustaceana: Euphausiacea). J Crustac Biol 7:518-527

Cuzin-Roudy J (1993) Reproductive strategies of the Mediterranean krill, Meganyctiphanes norvegica and the Antarctic krill Euphausia superba (Crustacea: Euphausiacea). Invertebr Reprod Dev 23:105-114
Cuzin-Roudy J (2000) Seasonal reproduction, multiple spawning, and fecundity in northern krill, Meganyctiphanes norvegica, and Antarctic krill, Euphausia superba. Can J Fish Aquat Sci 57:6-15

> Cuzin-Roudy J, Amsler MO (1991) Ovarian development and sexual maturity staging in Antarctic krill, Euphausia superba Dana (Euphausiacea). J Crustac Biol 11:236-249

Cuzin-Roudy J, Schalk P (1988) Macrozooplankton biomass, development and activity. The expedition ANTARCTIS VII/3 (EPOS leg 2) of RV Polarstern in 1989:146-159

> Dalpadado P, Ikeda T (1989) Some observations on moulting, growth and maturation of krill (Thysanoessa inermis) from the Barents Sea. J Plankton Res 11:133-139

- Daly KL (2004) Overwintering growth and development of larval Euphausia superba: an interannual comparison under varying environmental conditions west of the Antarctic Peninsula. Deep-Sea Res II 51:2139-2168

Dempster AP, Laird NM, Rubin DB (1977) Maximum likelihood from incomplete data via the EM algorithm. J R Stat Soc, B 39:1-38

Du J (2002) Combined algorithms for constrained estimation of finite mixture distirbutions with grouped data and conditional data. Masters thesis, McMaster University, Hamilton, Ontario, Canada

El-Sayed SZ, McWhinnie MA (1979) Antarctic krill: protein of the last frontier. Oceanus 22:13-20

> Ettershank G (1983) Age structure and cyclical annual size change in the Antarctic krill Euphausia superba Dana. Polar Biol 2:189-193

Everson I (1977) The living resources of the Southern Ocean. Southern Ocean Fisheries Survey Programme GLO/SO/ 77/1, FAO, Rome

- Farber-Lorda J (1990) Somatic length relationships and ontogenic morphometric differentiation of Euphausia superba and Thysanoessa macrura of the southwest Indian Ocean during Summer (February 1981). DeepSea Res 37:1135-1143

Goebel ME, Lipsky JD, Reiss CS, Loeb VJ (2007) Using carapace measurements to determine the sex of Antarctic krill, Euphausia superba. Polar Biol 30:307-315

Gulland JA (1983) The development of fisheries and stock assessment of resources in the Southern Ocean. Mem Natl Inst Polar Res 27:129-152

Hilborn R, Walters CJ (1992) Quantitative fisheries stock assessment: choice, dynamics and uncertainty. Chapman \& Hall, New York, NY

Hill SL, Cannon M (2013) A potential feedback approach to ecosystem-based management: model predictive control of the Antarctic krill fishery. CCAMLR Sci 20:119-137

Hill SL, Keeble K, Atkinson A, Murphy EJ (2012) A foodweb model to explore uncertainties in the South Georgia shelf pelagic ecosystem. Deep-Sea Res II 59-60:237-252

Hosie GW, Ritz DA (1989) Body shrinkage in the subtropical euphausiid Nyctiphanes australis G.O. Sars. J Plankton Res 11:595-598

> Ikeda T, Dixon P (1982) Body shrinkage as a possible overwintering mechanism of the Antarctic Krill, Euphausia superba Dana. J Exp Mar Biol Ecol 62:143-151

Ikeda T, Thomas PG (1987) Molting interval and growth of juvenile Antarctic krill (Euphausia superba) fed different concentrations of the diatom Phaeodactylum tricornutum in the laboratory. Polar Biol 7:339-343

> Jones CD, Ramm DC (2004) The commercial harvest of krill in the southwest Atlantic before and during the CCAMLR 2000 Survey. Deep-Sea Res II 51:1421-1434

Kawaguchi S, Nicol S (2007) Learning about Antarctic krill from the fishery. Antarct Sci 19:219-230 
Kawaguchi S, Candy S, Nicol S, Taki K, Naganobu M (2005) Analysis of trends in Japanese krill fishery CPUE data, and its possible use as a krill abundance index. CCAMLR Sci 12:1-28

Kawaguchi S, Candy SG, King R, Naganobu M, Nicol S (2006) Modelling growth of Antarctic krill. I. Growth trends with sex, length, season, and region. Mar Ecol Prog Ser 306:1-15

Kawaguchi S, Finley LA, Jarman S, Candy SG and others (2007) Male krill grow fast and die young. Mar Ecol Prog Ser 345:199-210

Kinzey D, Watters GM, Reiss CS (2015) Selectivity and two biomass measures in an age-based assessment of Antarctic krill (Euphausia superba). Fish Res 168:72-84

Lasker R (1966) Feeding, growth, respiration and carbon utilization of a euphausiid crustacean. J Fish Res Board Can 23:1291-1317

Macdonald PDM, Pitcher TJ (1979) Age-groups from sizefrequency data: a versatile and efficent method of analysing distribution mixtures. J Fish Res Board Can 36: 987-1001

Mackintosh NA (1972) Life-cycle of Antarctic krill in relation to ice and water conditions. Discov Rep 36:1-94

Makarov RR (1976) Reproduction of Euphausia superba (Dana) (Crustacea: Euphausiacea). Proc All-Union Sci Res Inst Mar Fish Oceanogr 110:85-89 (translated from Russian)

Marr JWS (1962) The natural history and geography of the Antarctic krill. Discov Rep 32:33-464

> McClatchie S (1988) Food-limited growth of Euphausia superba in Admiralty Bay, South Shetland Islands, Antarctica. Cont Shelf Res 8:329-345

McWhinnie MA, Denys CJ, Parkin R, Parkin K (1979) Biological investigations of Euphausia superba (krill). Antarct J US 14:163-164

> Meyer B (2012) The overwintering of Antarctic krill, Euphausia superba, from an ecophysiological perspective. Polar Biol 35:15-37

Miller D, Agnew D (2000) Management of krill fisheries in the Southern Ocean. In: Everson I (ed) Krill biology, ecology and fisheries. Oxford Blackwell Science, p 300-337

Miller DGM, Hampton I (1989) Biology and ecology of the Antarctic krill, Vol 9. SCOR, Cambridge, UK

Morris DJ, Watkins JL, Ricketts C, Buchholz F, Priddle J (1988) An assessment of the merits of length and weight measurements of Antarctic krill Euphausia superba. Br Antarct Surv Bull 79:27-50

Nicol S (2000) Understanding krill growth and aging: the contribution of experimental studies. Can J Fish Aquat Sci 57:168-177

Nicol S, Stolp M, Cochran T, Geijsel P, Marshall J (1992) Growth and shrinkage of Antarctic krill Euphausia superba from the Indian Ocean sector of the Southern Ocean during summer. Mar Ecol Prog Ser 89:175-181

Pitcher T, MacDonald P (1973) Two models for seasonal growth in fishes. J Appl Ecol 10:599-606

Pond D, Watkins J, Priddle J, Sargent J (1995) Variation in the lipid content and composition of Antarctic krill Euphausia superba at South Georgia. Mar Ecol Prog Ser 117:49-57

Quetin LB, Ross RM (1991) Behavioural and physiological characteristics of Antarctic krill Euphausia superba Dana. Am Zool 31:49-63

Quetin LB, Ross RM, Clarke A (1994) Krill energetics: seasonal and environmental aspects of the physiology of Euphausia superba. In: El-Sayed SZ (ed) Southern Ocean Ecology: the BIOMASS perspective. Cambridge
University Press Cambridge, p 165-184

Quetin LB, Ross RM, Frazer TK, Amsler MO, Wyattevens C, Oakes SA (2003) Growth of larval krill, Euphausia superba, in fall and winter west of the Antarctic Peninsula. Mar Biol 143:833-843

Quinn TJ, Deriso RB (1999) Quantitative fish dynamics. Oxford University Press, Oxford

Reid K (2001) Growth of Antarctic krill Euphausia superba at South Georgia. Mar Biol 138:57-62

Rosenberg AA, Beddington JR, Basson M (1986) Growth and longevity of krill during the first decade of pelagic whaling. Nature 324:152-153

Schmidt K, Atkinson A, Steigenberger S, Fielding S and others (2011) Seabed foraging by Antarctic krill: implications for stock assessment, bentho-pelagic coupling, and the vertical transfer of iron. Limnol Oceanogr 56: 1411-1428

Schmidt K, Atkinson A, Pond DW, Ireland LC (2014) Feeding and overwintering of Antarctic krill across its major habitats: the role of sea ice cover, water depth, and phytoplankton abundance. Limnol Oceanogr 59:17-36

Shelton AO, Kinzey D, Reiss C, Munch S, Watters G, Mangel M (2013) Among-year variation in growth of Antarctic krill Euphausia superba based on length-frequency data. Mar Ecol Prog Ser 481:53-67

Siegel V (1986) Untersuchungen zur Biologie des antarktischen Krill, Euphausia superba, im Bereich der Bransfield Straße und angrenzender Gebiete. Mitt Inst Seefischerei 38:1-244

Siegel V (1987) Age and growth of Antarctic Euphausiacea (Crustacea) under natural conditions. Mar Biol 96: 483-495

Siegel V (2000) Krill (Euphausiacea) life history and aspects of population dynamics. Can J Fish Aquat Sci 57:130-150

Siegel V (2012) Krill stocks in high latitudes of the Antarctic Lazarev Sea: seasonal and interannual variation in distribution, abundance and demography. Polar Biol 35: $1151-1177$

Siegel V, Loeb V (1994) Length and age at maturity of Antarctic krill. Antarct Sci 6:479-482

Siegel V, Nicol S (2000) Population parameters. In: Everson I (ed) Krill biology, ecology and fisheries. Blackwell Science, Oxford, p 103-149

Stepnik R (1982) All year populational studies of Euphausiacea (Crustacea) in the Admiralty Bay (King George Island, South Shetland Islands, Antarctica). Pol Polar Res 3:49-68

Tarling GA, Cuzin-Roudy J, Thorpe SE, Shreeve RS, Ward P, Murphy EJ (2007) Recruitment of Antarctic krill Euphausia superba in the South Georgia region: adult fecundity and the fate of larvae. Mar Ecol Prog Ser 331: 161-179

Tarling GA, Klevjer T, Fielding S, Watkins JL and others (2009) Variability and predictability of Antarctic krill swarm structure. Deep-Sea Res I 56:1994-2012

> Thomas P, Ikeda T (1987) Sexual regression, shrinkage, rematuration and growth in spent females Euphausia superba in the laboratory. Mar Biol 95:357-363

> Thorpe SE, Heywood KJ, Stevens DP, Brandon MA (2004) Tracking passive drifters in a high resolution ocean model: implications for interannual variability of larval krill transport to South Georgia. Deep-Sea Res I 51: 909-920

Thorpe SE, Murphy EJ, Watkins JL (2007) Circumpolar connections between Antarctic krill (Euphausia superba Dana) populations: Investigating the roles of ocean and sea ice transport. Deep-Sea Res I 54:792-810 